\title{
Role of Regulatory T Cells in the Helicobacter Pylori Infection
}

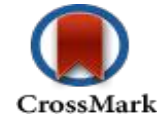

\author{
Tania Beatriz Romero-Adrián ${ }^{1,2^{*}}$ \\ ${ }^{1}$ Graduate Studies in Immunology, Faculty of Medicine, University of Zulia, Maracaibo, Venezuela \\ ${ }^{2}$ Institute of Biological Research, Faculty of Medicine, University of Zulia, Maracaibo, Venezuela
}

*Corresponding author: Tania Beatriz Romero-Adrian, Graduate Studies in Immunology, Institute of Biological Research, Faculty of Medicine, University of Zulia, 69 B Avenue, 77-49th Streets, Panamericano Sector, Maracaibo, Venezuela, Tel: +580261-7532659; Fax: +58-0261-7533822; E-mail: corporacionbiomedica.alt@gmail.com

Received date: December 24, 2016

Accepted date: January 21, 2016

Published date: January 25, 2016

Citation: Romero-Adrián, T.B., et al. Role of Regulatory T Cells in the Helicobacter Pylori Infection. (2016) J Gastrointest Disord Liver Func 1(2): 36-37.

Helicobacter pylori (H.pylori) is a gram-negative bacterium that affects more than half of the global human population. This microorganism shows variations in its geographical distribution and causes chronic gastritis, peptic ulcer, gastric adenocarcinoma and mucosa-associated lymphoid tissue lymphoma. Investigations have implicated regulatory T cells (Tregs) in the pathogenesis of the H.pylori infection. Treg cells suppress excessive activation of $\mathrm{CD}^{+}$as well as $\mathrm{CD} 8^{+}$for controlling gastric inflammation and persistent colonization of the bacterium ${ }^{[1,2]}$.

Studies have demonstrated that H.pylori-infected individuals have increased frequencies of CD4 ${ }^{+} \mathrm{CD} 25^{\text {high }} \mathrm{T}$ cells in both the stomach and duodenal mucosa compared to uninfected controls. These cells express FOXP3, a key gene for the development and function of regulatory T cells, as well as high levels of the cytotoxic T lymphocyte-associated antigen 4 (CTLA-4) proteins. Mucosal $\mathrm{CD} 4^{+} \mathrm{CD} 25^{\text {high }} \mathrm{T}$ cells are present in individuals with asymptomatic H.pylori infections as well as in duodenal ulcer patients. The frequencies of $\mathrm{CD} 4^{+} \mathrm{CD} 25^{\text {high }}$ cells are also increased in the stomachs of H.pylori-infected patients with gastric adenocarcinoma. These findings suggest that regulatory $\mathrm{T}$ cells may suppress mucosal immune responses and thereby contribute to the persistence of H.pylori infections ${ }^{[3]}$. Researchers has demonstrated that the number of Tregs is elevated and positively correlated with histological grade of chronic gastritis, atrophic gastritis and adenocarcinoma, but is decreased and negatively correlated with histological grade of intestinal metaplasia. However, the relationship between $\mathrm{CD} 4^{+} \mathrm{CD} 25^{+}$Tregs and precancerous lesions of the stomach remain unclear $^{[4]}$.

The inability of patients to clear H.pylori infections is a consequence of active immunosuppression and evasion mechanisms of bacteria. Many immune factors are involved: Dendritic cells (DCs) exhaustion by chronic exposure of these cells to H.pylori, influence of the immunosuppressive cytokines secreted by Tregs cells, mast cells that change the gastric mucosal environments among others ${ }^{[2]}$. Regulations of the Th17/Treg and Th1/Treg balances are important in the response immune in the H.pylori infection. Depending of the functional activity and the secretion of cytokines such as Transforming Growth Factor- $\beta$ and Interleukin-10, the Tregs cells exert their immunosuppressive effects on other cellular phenotypes (Th1, Th2 and Th17). Therefore, to understand the development of Tregs during infection with H.pylori is crucial to interpret not only the immunopathogenic mechanisms involved but also multiple outcomes of the infection. The H.pylori infection is a multi-factorial pathology and each of the host (genetic and nutritional state) and bacterium (virulent strains and multiple strains) dependent factors have their influences on the immune system. The identification of regulatory $\mathrm{T}$ cells and of their cytokines at the site of H.pylori infection in humans may also have important implications for the understanding of immune responses to other infections and also, the disruption of Treg function could contribute to the development of diverse autoimmune and inflammatory diseases. Nowadays, it is considered that the FOXp3 gen could be a therapeutic target to control of H.pylori infection take into consideration its participation in the development and function of Tregs cells ${ }^{[1,2]}$ 


\section{References}

1. Romero-Adrián, T.B., Leal-Montiel, J., Monsalve-Castillo, F., et al. Helicobacter pylori: bacterial factors and the role of cytokines in the immune response. (2010) Curr Microbiol 60(2): 143-155.

2. Romero-Adriàn, T.B., Leal-Montiel, J. Helicobacter pylori infection: Regulatory $\mathrm{T}$ cells and their participation in the immune response. (2013) Jundishapur J Microbiol 6(4): e5183.

3. Lundgren, A., Strömberg, E., Sjöling, A., et al. Mucosal FOXP3-expressing $\mathrm{CD}^{+} \mathrm{CD}^{2} 5^{\text {high }}$ regulatory $\mathrm{T}$ cells in Helicobacter pylori-infected patients. (2005) Infect Immun 73(1): 523-531.

4. Cheng, H.H., Tseng, G.Y., Yang, H.B., et al. Increased numbers of Foxp3-positive regulatory T cells in gastritis, peptic ulcer and gastric adenocarcinoma. (2012) World J Gastroenterol 18(1): 34-43. 